\author{
Indah Sri Wahyuningsih ${ }^{1}$,Awal Prasetyo ${ }^{2}$, Reni Sulung Utami ${ }^{3}$ \\ ${ }^{1}$ Mahasiswa Magister Keperawatan, Fakultas Kedokteran, Universitas Diponegoro \\ ${ }^{2}$ Dosen Fakultas Kedokteran, Universitas Diponegoro \\ ${ }^{3}$ Dosen Departemen Keperawatan, Fakultas Kedokteran, Universitas Diponegoro
}

\begin{abstract}
ABSTRAK
Pasien kritis dewasa yang terpasang ventilator di ruang intensif seringkali menerima perawatan yang menyebabkan rasa nyeri. Nyeri merupakan gejala yang sering terjadi pada pasien kritis dewasa dengan ventilator dan bersifat individual. Penilaian nyeri pada pasien kritis dengan ventilator sangat diperlukan karena ketidakmampuan pasien dalam menyampaikan rasa nyeri secara verbal. Beberapa instrumen pengkajian nyeri untuk pasien kritis dewasa telah dikembangkan. Namun, belum ada instrumen yang valid dan reliabel untuk menilai nyeri. Studi literatur ini bertujuan untuk mengidentifikasi instrumen pengkajian nyeri pada pasien yang terpasang ventilator. Metode studi literatur dilakukan melalui penelusuran artikel publikasi pada MEDLINE, Googlesearch, PubMed serta Proquest dengan kata kunci pain assessment, tool, critical care, adult, critical ill, unconcious dan mechanical ventilation. Penelusuran literatur dari terbitan tahun 2000-2015 dengan desain penelitian crossectional, before and after study dan observational study. Hasil pengelompokkan studi sesuai karakteristik penelitian ditemukan lima instrumen pengkajian nyeri yaitu, NVPS, P.A.I.N, Comfort scale, BPS dan CPOT. Instrumen pengkajian CPOT memiliki nilai validitas dan reliabilitas yang lebih tinggi daripada keempat instrumen lainnya. Kelima instrumen pengkajian nyeri tersebut telah diukur validitas dan reliabilitasnya, namun belum pernah dilakukan uji sensitivitas dan spesifisitasnya. Sehingga diperlukan penelitian lebih lanjut terkait sensitivitas dan spesifisitas dari semua instrumen nyeri pada pasien kritis dewasa dengan ventilator.
\end{abstract}

Kata kunci : Pengkajian nyeri, penyakit kritis, dewasa, ventilator

\title{
LITERATURE REVIEW: PAIN ASSESSMENT TOOLS IN CRITICALLY ILL ADULT PATIENTS WITH VENTILATOR
}

\begin{abstract}
Critically ill adult patients with a ventilator in intensive care often receive treatment that causes pain. Pain is a symptom that often occurs in critically ill adult patients with ventilator and it is very individual. Pain assessment in critically ill patients with the ventilator is needed because of the patient unable to self-report of pain. Pain assessments critically ill adult patients have been developed. However, there is no valid and reliable instrument to assess pain. The objectives of the literature review are to identify the instruments of pain assessment in patients with ventilator. The method of literature was performed through seeking publication of articles in MEDLINE, Google Search, PubMed, and Proquest with keywords pain assessment, tool, critical care, adult, critically ill, unconscious and ventilator. Literatures were undertaken from 2000-2015 with a cross-sectional study design, before and after studies and observational study. The results of the study according to the characteristics of the research was found five pain assessment instruments, they were NVPS, P.A.I.N, Comfort scale, BPS and CPOT. The validity and reliability CPOT is highest among others. All instruments had been measured its validity and reliability, but it had never tested its sensitivity and specificity. So, more researches should be conducted related to the sensitivity and specificity of all the instruments of pain in critically ill adult patients with a ventilator.
\end{abstract}

Keywords : Pain assessment, critically ill, adult, ventilator.

Corresponding Author:

Indah Sri Wahyuningsih ${ }^{1}$, Master of Nursing Student, Medical Faculty, Diponegoro University

E-mail : indah_ners@ymail.com 


\section{PENDAHULUAN}

Pasien dewasa yang terpasang ventilator di ruang intensif seringkali menerima perawatan yang menyebabkan rasa nyeri. Nyeri merupakan gejala yang paling sering terjadi pada pasien yang terpasang ventilator dan bersifat individual dengan pengalaman nyeri yang berbeda- beda. Hampir lima juta pasien yang dirawat di ruang intensif, $71 \%$ diantaranya mengalami rasa nyeri selama perawatan (Stites, 2008). Rasa nyeri yang terjadi pada pasien dewasa yang terpasang ventilator disebabkan oleh penyakit patofisiologis, dampak dari terapi dan prosedur yang diberikan pada pasien (Cade, 2008). Prosedur keperawatan yang sering mengakibatkan nyeri diantaranya yaitu, perubahan posisi pasien, penghisapan lendir dari trakea pada pasien dengan ventilasi mekanik, penggantian balutan luka dan pemasangan ataupun pelepasan kateter (Puntilo et al, 2004; Dunn et al, 2009; Alderson et al, 2013; Sutari et al, 2014).

Penilaian nyeri yang sistematis dan konsisten dibutuhkan pada pasien kritis yang terpasang ventilator (Rahu et al, 2010). Akan tetapi, sebagian besar pasien yang terpasang ventilator tidak dapat mengkomunikasikan rasa nyerinya secara verbal sehingga diperlukan penilaian nyeri yang terstandar (Coyer et al, 2007). Penilaian tersebut dapat dilihat dari indikator perilaku, penelitian yang dilakukan pada 1144 pasien di Intensive Care Unit (ICU) dimana 513 pasien dilakukan penilaian nyeri dan 631 tidak dilakukan penilaian nyeri menunjukkan hasil bahwa pada pasien yang dilakukan penilaian nyeri dapat mengurangi durasi lama pemakaian ventilator ( 8 hari vs 11 hari, $p<0.01$ ) dan mengurangi lama perawatan di ICU (13 hari vs 18 hari, $\mathrm{p}<0.01$ ) (Puntilo et al, 1997, Payen et al, 2009).

Beberapa penelitian yang berkaitan efek penggunaan instrumen nyeri pada pasien dengan ventilator telah dipublikasikan (Gelinas et al, 2006; Payen et al, 2001; Gelinas et al, 2011). Akan tetapi, perlu dilakukan studi literatur lebih lanjut terkait validasi dari instrumen nyeri pada pasien dengan ventilator. Berdasarkan ulasan tersebut, penulis perlu melakukan studi literatur berkaitan dengan instrumen pengkajian nyeri yang bertujuan untuk mengidentifikasi validitas dan reliabilitas instrumen pengkajian nyeri pada pasien kritis dewasa yang terpasang ventilator

\section{METODE}

Penulisan artikel dalam studi literatur ini dilakukan penelusuran melalui EBSCO, Google Scholar, Proquest dan Pubmed dengan kata kunci pain assessment, tool, critical care, adult, critical ill, unconcious dan mechanical ventilation. Penelusuran literatur dimulai pada tahun terbit antara 20002015 untuk direview. Kriteria inklusi dari penelusuran literatur didapatkan dari jurnal dengan tipe penelitian crossectional, before- after study dan observational study. Adapun kriteria responden dalam review literatur adalah pasien kritis dewasa yang terpasang ventilator di ICU.

\section{HASIL}

Hasil penelusuran literatur diperoleh artikel berjumlah 16 dan diambil 9 artikel yang sesuai dengan kriteria inklusi. Sedangkan, 5 artikel dieksklusi karena penelitian dilakukan secara retrospektif. Instrumen pengkajian nyeri yang ditemukan berjumlah 5 diantaranya yaitu, Nonverbal Adult Pain Assessment Scale (NVPS), Pain Assessment and Intervention Notation Algorithm (P.A.I.N), Comfort Scale, Behavioural pain scale (BPS), dan Critical-Care Pain Observasion Tool (CPOT). 


\section{Nonverbal Adult Pain Scale (NVPS)}

NVPS dikembangkan oleh Odher et al pada tahun 2003 yang digunakan untuk mengukur nyeri pada pasien dewasa yang terintubasi dan tersedasi. NVPS merupakan instrumen pengkajian nyeri pengembangan dari instrumen pengkajian nyeri FLACC (Faces, Legs, Activity, Cry, Consolability). Komponen dari NVPS antara lain 3 indikator perilaku dan indikator fisiologi (tekanan darah, denyut jantung, respiratory rate, kulit). Penilaian dari masing- masing indikator tersebut dari skor 1 sampai 2 dengan total skor 0 (tidak nyeri) dan 10 (nyeri maksimal). Penelitian Odher et al (2003) dengan subjek penelitian pasien dewasa yang mengalami luka bakar, hasil penelitian menunjukkan bahwa NVPS memiliki nilai validitas 0.78 dengan instrumen pembanding FLACC. Kelebihan dari NVPS adalah nilai validitas yang cukup tinggi untuk menilai nyeri pada pasien dewasa, kekurangan NVPS adalah instrumen hanya dapat digunakan pada pasien yang tidak sadar dan tersedasi.

\section{Pain Assessment and Intervention Notation Algorithm (P.A.I.N.)}

P.A.I.N Algorithm dikembangkan oleh Puntilo et al pada tahun 1997. Instrumen tersebut terdiri dari 12 indikator perilaku dan 8 indikator fisiologi. P.A.I.N digunakan untuk menilai nyeri pasien post operasi di ICU yang terintubasi dan terpasang ventilator. Instrumen pengkajian nyeri tersebut digunakan untuk menilai ada tidaknya nyeri pada pasien post operasi, dimana indikator perilaku pasien dinilai dengan skala Numeric Rating Scale (NRS) dari skor 0- 10. Hasil penelitian Puntillo et al (1997) menunjukkan bahwa nilai reliabilitas antara indikator perilaku dengan penilaian NRS oleh perawat dengan nilai $r=0.24-0.77$. Nilai tersebut menunjukkan bahwa instrumen tersebut memiliki nilai reliabilitas yang sedang. Kelemahan instrumen P.A.I.N adalah memerlukan waktu yang lama untuk menilai nyeri pada pasien karena tersiri dari 12 indikator perilaku dan 8 indikator psikologis, selain itu penilaian indikator perilaku dinilai dari skala NRS yang dilihat dari sudut pandang perawat dengan skor 0-10.

\section{Comfort Scale}

Comfort Scale merupakan instrumen pengkajian nyeri yang dikembangkan oleh Ambuel et al pada tahun 1992. Comfort scale digunakan untuk mengukur tingkat distres psikologis pada pasien kritis anak- anak dibawah usia 18 tahun dan dewasa yang tersedasi dan terpasang ventilator (Ambuel et al, 1992; Azhkenazy et al, 2011). Komponen penilaian dari comfort scale terdiri dari 8 item indikator diantaranya, kewaspadaan, ketenangan, respon pernapasan, gerakan fisik, ketegangan wajah, gerakan otot, tekanan darah dan denyut nadi. Setiap item diukur dengan skala dari 1- 5, dimana 1 merupakan tingkat tertinggi tidak berespon dan 5 paling tidak nyaman. Penelitian Azhkenazy et al (2011) dilakukan pada pasien yang terpasang ventilator dengan usia dewasa lebih dari 18 tahun menunjukkan bahwa nilai validitas instrumen yaitu 0.49-0.74 dan reliabilitas dengan cronbach alpha 0.60- 0.66. Instrumen comfort scale memiliki kelebihan dan kelemahan, kelebihannya memiliki indikator psikologis dan indikator perilaku yang dinilai dari perilaku pasien sebagai tanda adanya nyeri, namun kelemahannya instrumen tersebut memiliki nilai validitas dan reliabilitas yang sedang jika digunakan untuk pasien dewasa dengan ventilator.

\section{Behavioral Pain Scale (BPS)}

Behavioral Pain Scale (BPS) adalah instrumen pengkajian nyeri pada pasien kritis yang dikembangkan oleh Payen et al tahun 2001. Komponen penilaian BPS terdiri dari tiga item, yaitu ekspresi wajah, 
pergerakan bibir atas dan komplians terhadap ventilator. Skor dari masing- masing item tersebut antara skor 1-4, dengan nilai total dari BPS berada dalam rentang skor 3 (tidak nyeri) sampai skor 12 (sangat nyeri). Hasil penelitian Aissaoui et al (2005) mengenai validitas dan reliabilitas pada pada 30 pasien di ICU dengan 360 pengamatan menunjukkan bahwa BPS memiliki nilai reliabilitas dengan cronbach alfa 0.72 , nilai interrater reliability antar 3 observer sebesar 0.95 , dan nilai validitas sebesar $\mathrm{P}<0.001$.

Penelitian Young et al (2006) menunjukkan bahwa nilai validitas internal pada pasien dilakukan perubahan posisi dengan Cronbach alpha 0.64 dan nilai interrater reliability $82 \%-91 \%$ saat istirahat, 36\%-46\% selama prosedur perubahan posisi. Penelitian lain Ahlers et al (2008) membandingkan antara BPS dan NRS oleh perawat pada 113 pasien kritis dengan ventilator, hasilnya menunjukkan bahwa nilai construct validity dengan $r=0.55, P<.001$ ketika BPS dibandingkan dengan nilai NRS perawat dan nilai interrater reliability $0.67(95 \% \mathrm{Cl}, 0.54-0.80)$. Berdasarkan beberapa penilitian tersebut menunjukkan bahwa kelebihan dari instrumen BPS adalah dapat digunakan pada pasien yang terintubasi dan tidak terintubasi pada pasien kritis di ICU dengan nilai validitas dan reliabilitas yang cukup tinggi.

\section{Critical-Care Pain Observasion Tool (CPOT)}

Critical-Care Pain Observasion Tool (CPOT) merupakan instrumen pengkajian nyeri yang dikembangkan oleh Gelinas et al pada tahun 2006. Instrumen pengkajian nyeri tersebut terdiri dari 4 item penilaian, setiap item memiliki kategori yang berbeda, yaitu ekspresi wajah, pergerakan badan, tegangan otot dan keteraturan dengan ventilator untuk pasien terintubasi dan pasien yang tidak terintubasi. Jumlah skor yang diperoleh dalam rentang 0-8. Hasil penelitian menunjukkan bahwa CPOT memiliki nilai inter-rater reliability yang cukup tinggi yang dinilai pada saat pasien istirahat dengan nilai 0,95- 1 dan setelah prosedur dengan nilai 0,86-1. Penelitian pada pasien bedah jantung menunjukkan bahwa CPOT memiliki nilai inter-rater reliability sebesar 0,981 (Gelinas et al, 2006; Marmo, 2009). Penelitian Vazquez et al (2011) pada 96 pasien dengan ventilator yang diteliti saat pasien istirahat dan prosedur alih baring dengan nilai discriminant validity: Mean score saat istirahat 0.27 (SD,0.64); selama prosedur 1.93 (SD, 1.41). Sedangkan, nilai reliabilitasnya dengan uji Kappa dengan nilai 0.97- 1. Hal ini menunjukkan bahwa CPOT memiliki nilai interrater reliability sangat bagus. Kelebihan dari CPOT adalah dapat digunakan untuk pengkajian nyeri pada pasien bedah dan non bedah yang ditunjukkan dengan nilai interrater reliability yang cukup tinggi, sedangkan kelemahannya adalah CPOT belum diujikan pada pasien dengan agitasi dan delirium pada pasien kritis di ICU.

\section{PEMBAHASAN}

Hasil dari studi literatur ditemukan 5 instrumen pengkajian nyeri pada pasien kritis dewasa yang terpasang ventilator. Kelima instrumen tersebut memiliki indikator penilaian yang berbeda- beda sehingga memiliki kelebihan dan kekurangan masing masing. Menurut Penulis kelima instrumen tersebut memiliki kesamaan untuk mengkaji nyeri pasien kritis dewasa dengan ventilator. Pada 3 instrumen NVPS, P.A.I.N, dan comfort scale memiliki beberapa kesamaan yaitu ketiganya merupakan instrumen pengkajian nyeri yang memiliki indikator perilaku dan fisiologis yang digunakan untuk menilai nyeri pasien kritis dewasa dengan ventilator. Namun kekurangannya, ketiga instrumen 
tersebut memiliki indikator fisiologis berupa tanda- tanda vital, dimana indikator tersebut kurang sensitif untuk menilai adanya nyeri pada pasien kritis yang terpasang ventilator. Rose et al (2012) melaporkan bahwa penilaian tanda- tanda vital (denyut jantung, tekanan darah, respon pernafasan) bukan merupakan pedoman utama dalam menilai nyeri pada pasien kritis dewasa. Hal tersebut dikarenakan tanda- tanda vital pasien bersifat fluktuatif, sehingga tidak dapat menggambarkan adanya nyeri pada pasien kritis. Nilai dari tanda- tanda vital dapat meningkat, menurun atau stabil selama prosedur yang menyebabkan nyeri (Arroyo et al, 2008; Payen JF, 2009). Hal ini terlihat dari hubungan antara fluktuasi tanda- tanda vital dengan skor perilaku dan pelaporan nyeri secara verbal bersifat lemah (Aissaoui et al, 2005; Gelinas et al, 2014).

Sebagian besar penelitian menunjukkan bahwa BPS dan CPOT merupakan instrumen pengkajian nyeri yang memiliki nilai reliabilitas dan validitas yang lebih tinggi. Penelitian Aissaoui et al (2005) menunjukkan bahwa Behaviour pain scale (BPS) digunakan untuk mengukur nyeri pada pasien dewasa yang terpasang ventilator dengan membandingkan penilaian fisiologis sebagai indikator penilaian nyeri yang dilihat dari subjektivitas perawat. Namun, tidak signifikan hubungan antara BPS dengan variabel fisiologis dengan nilai $r=0.16(P=0.13)$ untuk denyut jantung dan $r=-0.02(P=0.84)$ untuk MAP. Secara menyeluruh indikator perilaku lebih baik dibanding indikator fisiologis, karena indikator fisiologis tidak spesifik dalam menggambarkan adanya nyeri pada pasien (Gelinas et al, 2008).

Selain BPS, instrumen pengkajian nyeri lainnya yang memiliki nilai validitas dan reliabilitas lebih tinggi adalah СРОТ. Instrumen СРОТ memiliki empat domain berkaitan dengan perilaku dan dipergunakan untuk menilai nyeri pada pasien dewasa yang terpasang ventilator atau tanpa ventilator pada kasus bedah, medikal dan trauma di ICU. CPOT memiliki nilai discriminant validity yang cukup bagus dengan mengobservasi pasien saat istirahat dan selama prosedur yang menyebabkan nyeri dengan nilai interrater reliability cukup tinggi yaitu 0.52- 0.88 (Payen et al, 2001; Gelinas et al, 2006). Selain itu, CPOT juga telah diuji sensitivitas dan spesifisitasnya dengan gold standard pelaporan nyeri secara verbal oleh pasien yang telah diekstubasi dengan hasil nilai sensitivitas $86 \%$ dan nilai spesifisitas $78 \%$ (Gelinas et al, 2009). Akan tetapi, CPOT tidak digunakan untuk menilai tingkat nyeri, namun untuk mendeteksi adanya nyeri pada pasien kritis dewasa dengan ventilator. Metode validasi untuk menilai tingkat nyeri pada pasien tidak berhasil (Pasero, 2005).

Diantara kelima instrumen pengkajian nyeri tersebut, BPS dan CPOT merupakan instrumen pengkajian nyeri yang valid dan reliabel untuk menilai adanya nyeri pada pasien kritis dewasa yang tidak mampu melaporkan nyeri secara verbal. Nilai reliabilitas dan validitas pada instrumen BPS dan СРОТ lebih tinggi dari ketiga instrumen lainnya. Akan tetapi, beberapa penelitian menunjukkan bahwa CPOT memiliki nilai validitas dan reliabilitas yang lebih tinggi daripada BPS. Kelebihan instrumen pengkajian nyeri СРOT lebih spesifik digunakan pada pasien yang tidak mampu mengkomunikasikan nyeri secara verbal dan telah diimplementasikan pada pasien dengan kasus trauma kepala, post operasi jantung, penyakit medikal di ICU.

\section{SIMPULAN DAN IMPLIKASI PENELITIAN}

Pengkajian nyeri pada pasien yang tidak mampu melaporkan rasa nyeri secara verbal merupakan kebutuhan utama yang perlu dilakukan secara rutin. Dari kelima instrumen pengkajian nyeri sesuai ulasan di atas, didapatkan nilai validitas dan reliabilitas dari masing- masing instrumen pengkajian 
nyeri. Instrumen pengkajian nyeri CPOT menunjukkan nilai validitas dan reliabilitas yang lebih tinggi daripada keempat instrumen pengkajian nyeri lainnya. Instrumen tersebut dapat digunakan untuk menilai nyeri pada pasien kritis dewasa baik terpasang ventilator maupun tidak dan telah digunakan pada pasien kritis dengan kasus medikal, bedah dan trauma.

Pengkajian nyeri secara sistematik diperlukan sebagai bagian dari proses perawatan. Pengkajian tersebut bertujuan untuk mengevaluasi nyeri pada pasien yang bersifat individual. Instrumen pengkajian nyeri pada pasien kritis dewasa telah diteliti validitas dan reliabilitasnya, akan tetapi diperlukan penelitian terbaru mengenai sensitivitas dan spesifisitas pada semua instrumen pengkajian nyeri yang diterapkan pada pasien kritis yang mengalami gangguan neuromuscular, agitasi, dan delirium

\section{DAFTAR PUSTAKA}

Ahlers, G., Veen, AV., Dongen, HV., Bruins P., \& Belitser S. (2008) . Comparison of different pain scoring systems in critically ill patients in a general ICU. Critical Care, 12(1):1-8.

Aissaoui, Y., Zeggwagh, A., \& Zekraoui, A. (2005) . Validation Of a Behavioral Pain Scale In Critically III, Sedated And Mechanically Ventilated Patients. Anesthiology Journal, 101:1470-6.

Alderson, SM., Mckechnie, SR. (2013). Unrecognised, undertreated, pain in ICU : causes, effects and how to do better. Open Journal Nurs, 108-13.doi.org/10.4236/ojn.2013.31014

Arroyo, CM., Figueroa., Puntillo, KA., Stanik-Hutt, J., Thompson, CL., White, C.(2008). Pain related to tracheal suctioning in awake acutely and critically ill adults: A descriptive study. Intensive Crit Care Nurs. 24(1):20-7.

Ashkenazy, S., \& DeKeyser. (2011). Assessment of the reliability and validity of the Comfort Scale for adult intensive care patients. Heart Lung Journal.

Bear, LA., Ward, S. (2006). Interrater reliability of the COMFORT scale. Pediatric Nurs, 32(5):427.

Cade CH. (2008). Clinical tools for the assessment of pain in sedated critically ill adults. Nurs Critical Care,13(6):288-97. doi:10.1111/j.1478-5153.2008.00294.x

Coyer ,FM., Wheeler, MK., Wetzig, SM., \& Couchman, BA. (2007). Nursing care of the mechanically ventilated patient: What does the evidence say. Part two. Intensive Crit Care Nurs, 23(2):71-80.

Dunn, W., \& Murphy, J. (2009). Should intensive care medicine it self be on the critical list? Chest;135(4):892-4.

Gelinas, C., Fillion, L., Puntillo, K., Viens, C., Fortier M., \& City Q. (2006). Validation of the Critical Care Pain. American Journal of Critical Care,15(4):18-20.

Gelinas, C., Fillion, L., Puntillo,K. (2008). Item Selection and Content Validity of the Critical Care Pain Observational Tool for Non verbal Adults. Journal of Advanced Nursing. 203-2016.

Gelinas, C., Harel, F., Fillion, L., Puntillo KA., \& Johnston, CC. (2009) Sensitivity and Specificity of the Critical-Care Pain Observation Tool for the Detection of Pain in Intubated Adults After Cardiac Surgery. Journal Pain Symptom Management, 37(1):58-67.

Gelinas, C., Arbour, C., Michaud, C., Vaillant, F., \& Desjardins, S. (2010). Implementation of the critical-care pain observation tool on pain assessment/management nursing practices in an intensive care unit with nonverbal critically ill adults: a before and after study. International of Journal Nursing Studies, 48(12):1495-504.

Gelinas, C., Benites, C., Kapuostino, O. (2014). Validation of The Use of The Critical-Care Pain Observation Tool (CPOT) With Brain Surgery Patients In The Neurosurgical Intensive Care Unit. Intensive and Critical Care Nursing, 30, 257-265

Marmo, L., \& Fowler S. (2009). Pain Assessment Tool in the Critically III Post Open Heart Surgery Patient Population. Pain Management Nursing, 11(3), 134-140. 
Odhner, M., Wegman, D., \& Freeland, N. (2003). Assessing pain control in nonverbal critically ill adults. Journal of Research in Medical Science, 22:260-7.

Pasero, C., Puntillo, K., \& Li D. Structured approaches to pain management in the ICU. Chest, 135:1665-72.

Payen, J., Bru, O., Bosson, J., Lagrasta A. (2001). Assessing pain in critically ill sedated patients by using a behavioral pain scale. Critical Care Med, 29(12)

Payen JF. (2009). Assessing Pain in Non Intubated Critically III Patients Unable to Self Report: An Adaptation of The Behavioral Pain Scale. Intensive Care Medicine. 35: 2060-2067.

Puntilo, K., Miaskowski, C., Kehrle, S., \& Gleeson S. (1997). Relationship between behavioural and psychological indicators of pain, critical care patients self report of pain and opioid administration. Critical Care Medicine, 1159-66.

Puntillo, K., Morris, AB., Thompson, CL., Stanik-Hutt, J., White, C., Wild LR. (2004) Pain behaviors observed during six common procedures: results from Thunder Project II. American Journal of Critical Care, 32(2):421-7.

Sutari, M., Abdalrahim, MS., Hamdan-mansour, AM., \& Ayasrah,SM. (2014). Pain among mechanically ventilated patients in critical care units. Journal of Research in Medical Science

Stites M. (2013). Observational Pain Scales in Critically III Adults. American Association of Critical-care Nurses, 33(3): 68-79.

Young, J., Siffleet, J., \& Nikoletti S. Use of a Behavioural Pain Scale to Assess Pain in Ventilated, Unconscious and/or Sedated Patients. Intensive Critical Care Nursing, 22:32-9.

Rahu, M., \& Grap, M. (2010). Facial expression and pain in the critically ill non-Communicative patient: state of science review. Intensive Critical Care Nursing, 26:343-52.

Rose, L., Smith, O., Gelinas, C., Haslam, L., Dale, C. (2012) Critical care nurses' pain assessment and management practices: A survey in Canada. American Journal of Critical Care, 21(4):251-9.

Vazquez, M., Pardavila, M., Lucia, M., Aguado Y., Margall, MÁ., Asiain, MC. (2011). Pain assessment in turning procedures for patients with invasive mechanical ventilation. Nursing Critical Care,16(4):178-85. 